\title{
A CONSTRUÇÃO SÓCIO-SEMIÓTICA DO SUJ EITO EXPERTO EM TRADUÇÃO ATRAVÉS DA ENCENAÇÃO E REPRESENTAÇÃO EM RELATOS RETROSPECTIVOS
}

\author{
Giacomo Figueredo \\ Cristiano Gonçalves Araújo
}

\begin{abstract}
RESUMO
Este trabalho explora, dentro de uma abordagem sócio-semiótica (HALLIDAY, 1978), contribuições para o conhecimento sobre a expertise em tradução (DIMITROVA, 2005) a partir da análise linguística dos textos que tratam da atividade do tradutor experto. Busca-se identificar como os significados produzidos pelo pesquisador e pelo sujeito se complementam na caracterização da expertise (MATTHIESSEN, 1998).

PALAVRAS-CHAVE: Estudos Descritivo da Tradução; Expertise em Tradução; Construção Sócio-Semiótica.
\end{abstract}

\section{Introdução}

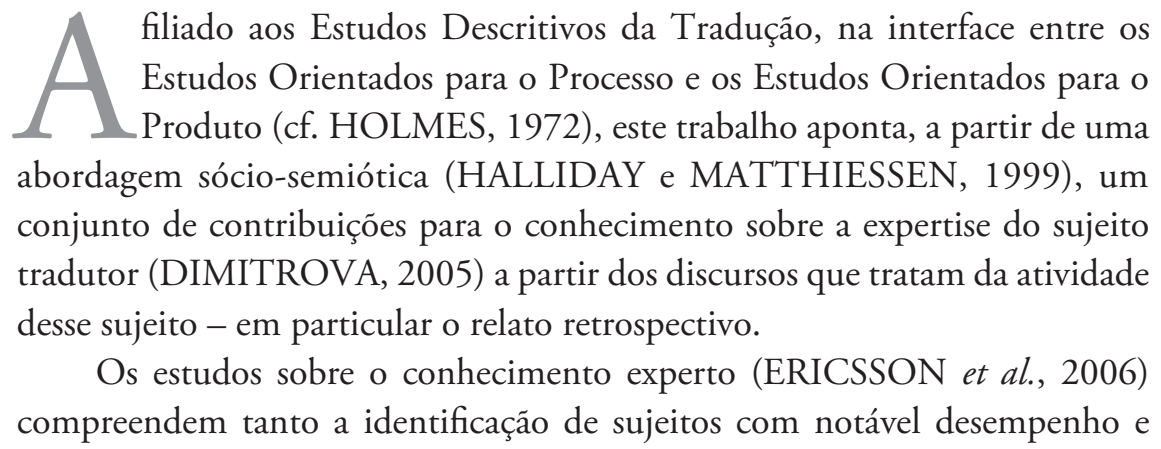


mapeamento das circunstâncias que propiciaram a emergência de tal desempenho (CHI, 2006). No escopo dos Estudos da Tradução, mapeamento do conhecimento experto se configura como uma das áreas de interesse crescente (ERICSSON e SMITH, 1991). Verificam-se, por conseguinte, vária pesquisas (DIMITROVA, 2005; SHREVE, 2006) e projetos de pesquisas - EXPERT@ (ALVES et al., 2006); PETRA (MUÑOZ, 2009) - cujas pesquisas caminham para a identificação das características que definem o tradutor experto.

Este trabalho toma como base as relevantes contribuiçóes do projeto EXPERT@e, a partir dele, busca identificar como os significados produzidos pelo pesquisador e pelo sujeito pesquisado se complementam na caracterizaçáo da expertise do sujeito. Tenciona-se ainda apontar como, nos relatos retrospectivos, há uma troca (i.e. negociação) de significados entre o pesquisador e o sujeito, em oposiçáo a uma reconstruçáo individual verbalizada dos processos cognitivos engendrados pelo sujeito, como é comumente aceito (cf. ERICSSON e SMITH, 1991; DIMITROVA, 2005; SHREVE, 2006).

A partir destas consideraçóes, o objetivo deste trabalho é oferecer uma leitura sócio-semiótica da construção do sujeito experto em tradução, com o intuito de acrescentar o elemento social à caracterização cognitivista desse sujeito. Esta leitura tem como base a Teoria Sistêmico-Funcional (HALLIDAY e MATTHIESSEN, 1999), a qual se apresenta como uma complementação linguística às abordagens cognitivas, uma vez que a língua é um recurso coletivo, fundador da intersubjetividade (MATTHIESSEN, 1998).

Foram, neste trabalho, analisados dois processos sócio-semióticos de um relato retrospectivo, nomeadamente os processos Relatar e Explorar (MATTHIESSEN et al., 2010). Os resultados da análise mostram como, ao se considerar o processo Relatar, a representação sócio-semiótica enfatiza a construção ideacional do sujeito experto; o processo Explorar, enfoca-se em como as relaçóes interpessoais mantidas entre o pesquisador e o sujeito do relato constroem representaçôes da experiência por meio da negociação de significados.

\section{A seleção de sujeitos expertos}

No projeto EXPERT@ - cujo objetivo geral é o mapeamento do perfil de tradutores expertos - os parâmetros utilizados para a seleção do grupo de sujeitos expertos são a experiência profissional e, principalmente, o reconhe- 
cimento pelos pares, na figura de "indivíduos com destacado desempenho, cuja excelência é acreditada com base na aferição de seus textos traduzidos, por parte de instituições que participam da produção, circulação e consumo desses textos" (ALVES et al., 2006, p. 3). A seleção embasada no reconhecimento pelos pares e experiência profissional recebe amplo respaldo da literatura (SOSNIAK, 2006; HOFFMAN e LINTERN; 2006); contudo, impóe uma dificuldade para se trabalhar no contínuo novato - experto, uma vez que o reconhecimento social da experiência e da capacidade do indivíduo determinam, em grande medida, o perfil do sujeito como experto antes mesmo da investigação em laboratório.

Pode-se vislumbrar, por isto, o motivo pelo qual o método de seleção dos sujeitos a serem incluídos nas pesquisas sobre o conhecimento experto em traduçáo náo se remete diretamente às abordagens cognitivas, visto que a etapa inicial da pesquisa envolve a consideraçáo da forma de inserção do indivíduo no meio social do qual faz parte. Assim, tem-se, por um lado, o objetivo de mapear aspectos cognitivos do processo tradutório de sujeitos expertos, fundamentando-se nas abordagens cognitivas; e, por outro, como primeira etapa da pesquisa, a orientaçáo de se selecionar sujeitos a priori, a partir do reconhecimento social.

Considerando-se que a língua é o meio pelo qual os indivíduos se tornam sujeitos semióticos - i.e., produtores de significado (HALLIDAY, 1978) - a semiótica social pode oferecer uma resposta positiva para este tipo de impasse, uma vez que explica como os significados produzidos no texto do relato retrospectivo ajudam a construir uma representaçấo do sujeito como (não) experto em sua área de atuação.

A contribuição deste trabalho para a identificação e seleção do sujeito experto por meio do reconhecimento social (i.e., a construção sócio-semiótica do sujeito experto em traduçáo) se refere à organizaçáo dos significados linguísticos no escopo da teoria sistêmico-funcional (HALLIDAY e MATTHIESSEN, 1999), a qual é apresentada a seguir.

\section{Contribuições semiótico-socias na seleção do 'experto'}

Estratificaçáo $\rightarrow$ Em uma perspectiva sócio-semiótica, o conceito de 'sujeito' se define como: o produtor de significados em uma comunidade dis- 
cursiva. Devido ao fato de a língua ser um sistema estratificado, ela é organizada pelo princípio de realização, que relaciona a produção linguística à organização social. Os estratos são caracterizados como: fonológico (expressão); lexicogramatical (organização funcional); semântico (textos e discurso); contextual (contexto de situação social/semiótico).

Uma vez que os significados são produzidos, por um lado, a partir de uma determinada organização funcional, e, por outro lado, em um dado contexto de situação, diz-se que qualquer produção de significados ocorre concomitantemente em todos os estratos (princípio de metarredundância) (HALLIDAY e MATTHIESSEN, 1999). Com efeito, a descrição dos sistemas lexicogramaticais explica como são produzidos os textos, que por sua vez são a realização semiótica do contexto de situação social.

Metafunção $\rightarrow$ O sujeito usa a língua para produzir significados, os quais servem para desempenhar papéis sociais (sistemas interpessoais de FUNÇÕES DISCURSIVAS, MODO e VALIDAÇÃO) e construir suas representaçôes da experiência de mundo (sistema ideacional de TRANSITIVIDADE) (HALLIDAY e MATTHIESSEN, 1999).

Do ponto de vista interpessoal, a oração é entendida como um argumento na troca entre os falantes. As FUNÇÓES DISCURSIVAS são um sistema semântico responsável por realizar as negociações entre os interlocutores. As proposiçóes se caracterizam pela troca de declaraçóes e perguntas, enquanto as propostas pela troca de comandos e ofertas. Os argumentos respondentes variam conforme a função discursiva, bem como com a disposição do interlocutor ouvinte de se engajar na interação (Quadro 1). 


\section{QUADRO 1}

Exemplos de argumentos respondentes às FUNÇÕES DISCURSIVAS.

\begin{tabular}{|c|c|c|}
\hline Inicial & Respondente & arbitrária \\
\hline $\begin{array}{l}\text { DECLARAÇÃo } \\
\text { Veio sete zero. }\end{array}$ & $\begin{array}{l}\text { RECONHECIM ENTO } \\
\text { Partícula M odal: } \\
\text { É?; Ah é? } \\
\text { ou declaração de concordância: } \\
\text { Tá bom. }\end{array}$ & $\begin{array}{l}\text { CONTRADIÇ̃̃O } \\
\text { NEG + declaração } \\
\text { contraditória: } \\
\text { Não. Veio sete um. }\end{array}$ \\
\hline $\begin{array}{l}\text { PERGUNTA ELEM ENTAL } \\
\text { Onde está? }\end{array}$ & $\begin{array}{l}\text { RESPOST A } \\
\text { Elemento faltante: } \\
\text { Aqui. }\end{array}$ & $\begin{array}{l}\text { RENÚNCI A } \\
\text { declaração negativa: } \\
\text { Sei lá. }\end{array}$ \\
\hline $\begin{array}{l}\text { PERGUNTA POLAR } \\
\text { Posso fazer a pergunta? }\end{array}$ & $\begin{array}{l}\text { RESPOSTA } \\
\text { Finito: } \\
\text { Pode }\end{array}$ & $\begin{array}{l}\text { RENÚNCIA } \\
\text { NEG: } \\
\text { Não. }\end{array}$ \\
\hline $\begin{array}{l}\text { COM ANDO } \\
\text { Apanha o fósforo aí. }\end{array}$ & $\begin{array}{l}\text { OBEDIÊNCIA } \\
\text { Predicador repetido como Finito no presente simples: } \\
\text { Apanho. } \\
\text { Expr essão de compromentimento (or ação menor): } \\
\text { tudo bem, perfeitamente, claro... }\end{array}$ & $\begin{array}{l}\text { RECUSA } \\
\text { NEG: } \\
\text { Não. } \\
\text { NEG + Predicador repetido } \\
\text { como Finito no presente } \\
\text { simples: } \\
\text { Não apanho. } \\
\end{array}$ \\
\hline $\begin{array}{l}\text { OFERT A } \\
\text { Quer que eu fale com ela? }\end{array}$ & $\begin{array}{l}\text { ACEITE } \\
\text { expressão de aceite (or ação menor): } \\
\text { por favor; obrigado... } \\
\text { Finito: } \\
\text { Quero. }\end{array}$ & $\begin{array}{l}\text { REJEIÇÃO } \\
\text { NEG + expressão de aceite: } \\
\text { não precisa; não, obrigado... } \\
\text { NEG: } \\
\text { Nẫo. }\end{array}$ \\
\hline
\end{tabular}

As FUNÇÕES DISCURSIVAS são realizadas pelos sistemas gramaticais de MODO e VALIDAÇÃO em português brasileiro. O Modo Indicativo realiza as proposiçóes e compreende tanto as oraçóes declarativas quanto as interrogativas. Já o Modo Imperativo realiza os comandos. Gramaticalmente, a principal função que realiza as orações indicativas é o Finito. As imperativas, por sua vez, têm como principal função o Predicador.

O Sujeito é, igualmente, uma função primordial para a realização da troca, uma vez que é este elemento que forma junto com a função determinante do MODO (Finito ou Predicador) o núcleo da "arguabilidade" das proposiçóes e propostas. A este conjunto de funçôes que formam o núcleo de significados interpessoais na oração dar-se-á o nome de Negociador (FIGUEREDO, 2011).

O sistema de VALIDAÇÃO, realizadas pelas Partículas Modais, negocia algum aspecto da oração como argumento da interação. Por conseguinte, os elementos interpessoais da oração que formam as opçóes deste sistema também são incluídos como parte do Negociador, juntamente com o Sujeito e o Finito (ou Predicador). 
O diálogo pode então ser visto como o processo negociado de converter as opinióes dos interlocutores em "conhecimento compartilhado". Em geral, o falante procura aplicar toda a dispersão dos recursos (modalização, partículas, entonação, etc.) que possam aumentar as chances de suas opiniôes serem aceitas pelo grupo com o qual interage. Neste sentido, o conceito de 'verdade' não é interpretado como uma questão ideacional, mas sim interpessoal. Isto porque o que é 'válido e inválido' é o resultado do processo de negociação (cf. HALLIDAY e MATTHIESSEN, 2004, p. 117), e não dado pela organização da experiência.

Do ponto de vista ideacional, a língua representa os eventos no mundo e as experiências do falante. Por meio do sistema gramatical de TRANSITIVIDADE, o falante constrói suas percepçóes dos fenômenos do mundo e de sua própria consciência; compreendendo os eventos que ocorrem ao redor do falante bem como de seu "mundo interno" e o entendimento tanto do mundo quanto da própria língua. Desta maneira, a TRANSITIVIDADE é o sistema gramatical que se ocupa com a expressão de 'conteúdo', quando a língua é sobre alguma coisa. As principais funçóes deste sistema são os Processos, caracterizados da seguinte forma em português brasileiro:

Materiais - indicam representações de transformação e acontecimento no mundo externo à consciência do sujeito. Mentais - representam os eventos de cognição, desejo, emoção e percepção do sujeito. Relacionais - indicam a representação simbólica entre signos por meio da atribuição de características ou da identidade. Verbais - representam a negociação com outros falantes das representaçóes mentais, por meio da fala. Existenciais - representam a introdução de um elemento no campo do contexto de situação.

Instanciação $\rightarrow$ A partir do contínuo da instanciação, as variaçóes de uso da língua constituem probabilidades e são condicionadas pelo contexto. Os extremos do contínuo são o potencial sistêmico da língua (o sistema como um todo) e a instância (os textos). Entre estes, encontram-se os registros, ou tipos textuais (HALLIDAY e MATTHIESSEN, 2004), os quais se identificam mais propriamente com as variaçóes de uso. O registro tem por característica apresentar uma configuração linguística própria que permite aos falantes predizerem sua produção. Neste artigo, trabalha-se a partir da tipologia textual da língua no contexto de cultura (MATTHIESSEN et al., 2010). Os processos 
sócio-semióticos são: Explicar; Relatar; Recriar; Compartilhar; Fazer; Recomendar; Habilitar; e Explorar. Estes representam as atividades de produção de significados de um sujeito, e dispõem de configuraçóes linguísticas próprias (Figura 1).

FIGURA 1 - Tipologia da língua no contexto de cultura. Fonte: traduzida e adaptada de Matthiessen et al., 2010, p. 221.

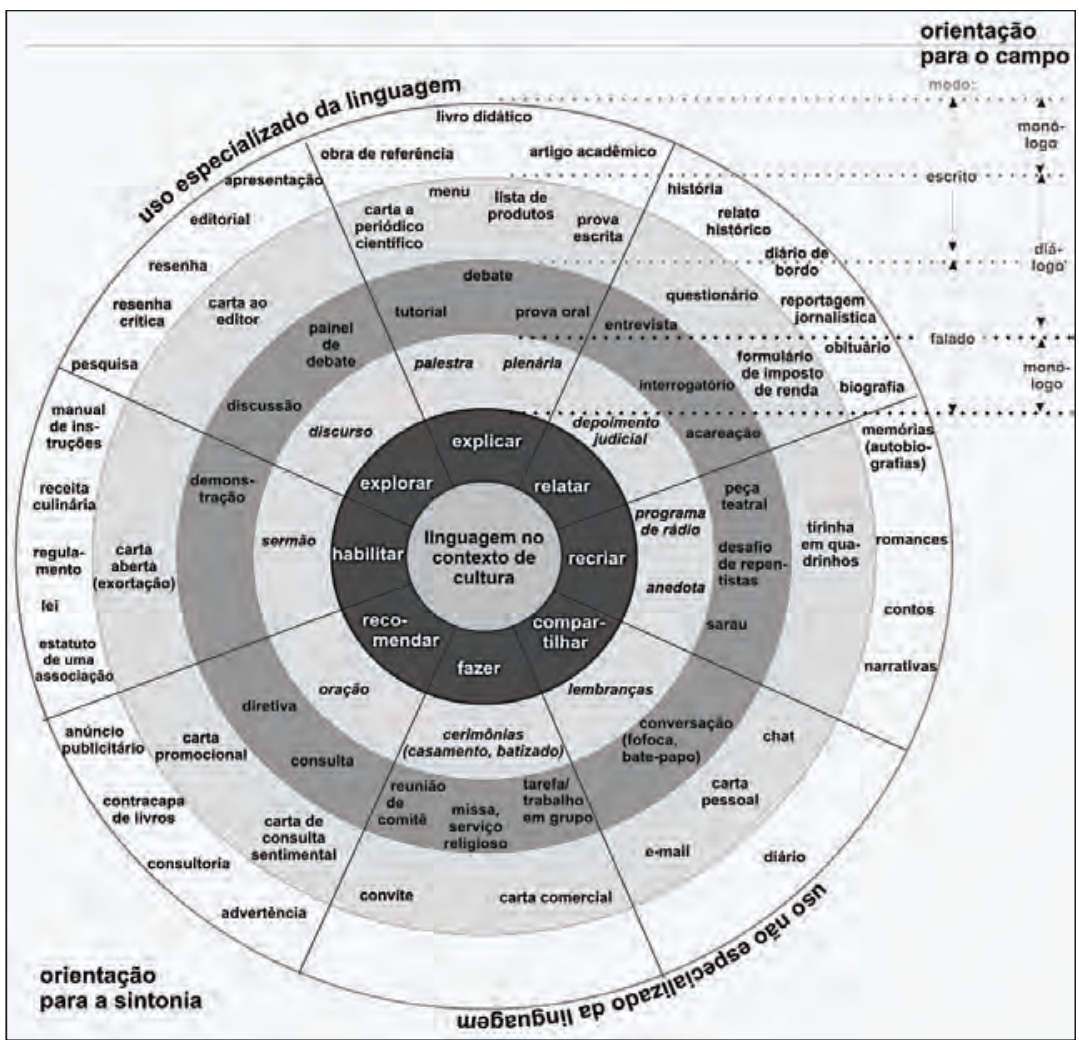

Ao combinar as dimensóes de estratificação e instanciação, tem-se que os significados são realizados nos estratos, pois possuem uma semântica (são textos), uma organizaçáo lexicogramatical, e desempenham uma função no contexto em que são produzidos; também, pode-se dizer que se configuram a partir de probabilidades de ocorrências no sistema, ou seja, como manifestaçóes dos registros. 


\section{METODOLOGIA}

O corpus foi composto por um relato retrospectivo dialogado. Este se caracteriza como a transcrição de um texto diálogo/oral e possui 5.685 tokens. $\mathrm{O}$ relato retrospectivo - a partir do qual se compilou o corpus da presente pesquisa - foi originalmente produzido durante um experimento de outra pesquisa conduzida no âmbito do EXPERT@ sobre expertise em tradução. Este relato foi produzido da seguinte forma: foi selecionado um sujeito para o experimento, considerado experto na área que atua em virtude do reconhecimento que recebe de seus pares e da experiência adquirida. $\mathrm{O}$ sujeito é um pesquisador experto na pesquisa médica, especialista em anemia falciforme.

Para o experimento, o sujeito recebeu a tarefa de traduzir do português para o inglês um texto sobre sua especialidade, anemia falciforme, e um outro, porquanto também da área de pesquisa médica, tratava de hepatite. As açóes da tradução de movimento do teclado foram registradas pelo programa Translog. Terminada a tradução, ao sujeito foi pedido que assistisse ao Replay do Translog, e que falasse sobre suas açôes em diálogo com os pesquisadores. O relato retrospectivo, foi gravado e, em seguida transcrito, compondo um texto escrito dos relatos retrospectivos que serviu como objeto de análise para o trabalho desses pesquisadores (cf. ALVES, 2001; JAKOBSEN, 2005).

\section{Metodologia de análise}

A metodologia de análise se baseia em metodologias semelhantes. Quant à análise de relatos para a identificação de padrôes lexicogramaticais, baseia-se em Alves e Magalhães (2006); e para a análise de tipos de texto sob uma perspectiva sócio-semiótica e de análise de registro, baseia-se em referência Herke-Couchman (2006), e Matthiessen et al. (2008).

O primeiro passo metodológico foi analisar o corpus a partir da visão de que a língua é entendida como sistema de produção de significados, e, por isto, (i) analisa-se a ligação do estrato mais alto do sistema linguístico, a semântica, ao contexto, é realizada de modo natural, como integração entre os sistemas do 'mundo externo' e os sistemas psicofisiológicos dos sujeitos; (ii) analisa-se o uso da língua pela probabilidade máxima de configuraçóes lexicogramaticais e semânticas (subsistemas) ocorrerem como realização de determinado con- 
texto. O segundo passo foi localizar as fases do texto do corpus nos processos sócio-semióticos - em torno dos usos possíveis da língua com respeito às atividades humanas, o que se faz em duas etapas: 1) identificação das configurações de relações de taxe e lógico-semânticas e 2) análise de padrôes de registro do subsistema instanciado no corpus. $\mathrm{O}$ terceiro passo foi a análise ideacional e a análise interpessoal da interação (HALLIDAY e MATTHIESSEN, 2004).

\section{Análise: contribuições da interpretação linguística para a sele- ção do sujeito experto em tradução}

Mediante análise, o relato foi dividido em duas partes. Na primeira, o sujeito respondeu a um questionário no qual relatou sua trajetória profissional, cuja evolução o conduziu, pelo reconhecimento dos pares e pela experiência, como um sujeito experto em sua área de atuação. Na segunda, assistiu ao Replay do Translog, procurando, no diálogo com os pesquisadores, produzir significados sobre sua experiência (ideacional) como tradutor, que responde às expectativas do reconhecimento pelos pares e consequente reconhecimento social (interpessoal).

Com isto, o corpus foi também dividido em duas partes. A primeira parte foi classificada segundo o processo sócio-semiótico Relatar, pois possui em posição temática o núcleo do texto que é, subsequentemente, desenvolvido em primeiro lugar por expansão/extensão e depois por expansão/elaboração e expansão/realce:

(1) Eu sou Professor Assistente <NÚCLEO > . Assistente 4. <ELABO$\mathrm{RAÇÃO}>\mathrm{E}$ atualmente eu dirijo um órgão complementar, que é o NUPAD, <REALCE $>$ aqui na Faculdade de Medicina. Tempo de serviço... $<$ EXTENSÃO $>$ Vinte e sete anos. Principais atividades exercidas... Foi como médico, né? <EXTENSÃO > Como clínico, que eu formei, que eu fiz residência em clínica médica. <ELABORAÇÃO > E como docente é... < ELABORAÇÃO > e também como pesquisador.

O processo sócio-semiótico Relatar possui orientação ideacional pelo fato de descrever a percepção sobre os eventos do mundo à volta dos sujeitos. Por isto, a análise do sistema de TRANSITIVIDADE foi necessária para esta porção do corpus: 
(2) Eu não tenho ainda meu doutorado, eu concluí <MATERIAL> meu...meu mestrado depois de muitos anos na faculdade, exatamente por uma característica inerente aqui da medicina, eu acho $<$ MENTAL $>$ que isso aconteceu <MATERIAL> com a...a minha geração de...de... de médicos, né, de docentes que na época isso não era tão importante, o importante era você saber $<$ MENTAL $>$, é...saber $<$ MENTAL > a medicina e saber ensinar $<$ MENTAL $>$. Mas, assim, eu...eu considero $<$ MENTAL $>$ isso, eu acho $<$ MENTAL $>$ que a experiência que eu adquiri $<$ MATERIAL $>$, acaba que você participa $<$ MATERIAL $>$ de uma série de outros trabalhos científicos, e acaba orientando $<$ MATERIAL $>$ pessoas. Então eu, acho $<$ MENTAL $>$ que cheguei $<$ MATERIAL $>$ num grau é...é...já compatível com um doutor, né? Ou talvez até um pós-doutor, mas o que eu preciso <MATERIAL > é de me titular, né? Eu preciso $<$ MATERIAL $>$ de for...que isso seja formalizado.

Os dados sobre a transitividade no processo Relatar indicam como o sujeito experto, ao ser estimulado pelo questionário dos pesquisadores a construir uma representação de suas atividades a realiza por meio de processos mentais e materiais. Os processos mentais indicam os fenômenos representados no "mundo interno" dos sujeitos (HALLIDAY e MATTHIESSEN, 1999). Mas, além disto, o subgrupo dos processos mentais, que inclui, por exemplo, os cognitivos (como 'pensar' e 'achar') e os desiderativos ('desejar' e 'esperar'), possui a capacidade de exteriorizar o mundo interno através do mecanismo de projeção, o que, em português brasileiro, se faz pela configuração gramatical de uma oração projetante, expressando o processo mental, e outra projetada, que expressa a ideia relativa ao "mundo interno" (FIGUEREDO, 2011).

No caso do sujeito do experimento, observa-se na trajetória de seu trabalho, que ao fim o levou a ser um pesquisador reconhecido em sua área de atuação, é fruto da representação linguística de atividades mentais sobre sua trajetória, transformadas em atividades materiais, principalmente por meio da projeção, como em:

(3)

\begin{tabular}{|l|l|}
\hline Então eu, acho $<$ MENTAL $>$ & $\begin{array}{l}\text { que cheguei }<\text { MATERIAL }>\text { num grau } \\
\text { é...é...já compatível com um doutor, né? }\end{array}$ \\
\hline oraçáo projetante - processo mental & $\begin{array}{l}\text { Oraçáo projetada - ideia - processo } \\
\text { material }\end{array}$ \\
\hline
\end{tabular}


(4)

\begin{tabular}{|l|l|}
\hline eu considero $<$ MENTAL $>$ & $\begin{array}{l}\text { que a experiência que eu adquiri }<\text { MATERIAL }>\text {, } \\
\text { acaba que você participa }<\text { MATERIAL }>\text { de uma série } \\
\text { de outros trabalhos científicos, e acaba orientando } \\
<\text { isso, eu acho }<\text { MENTAL }\end{array}$ \\
\hline $\begin{array}{l}\text { Oraçóes projetantes } \\
\text { processos mentais }\end{array}$ & - Oraçóes projetadas - ideias - processos materiais \\
\hline
\end{tabular}

Desta forma, seu relato é constituído por uma representação cognitiva de suas atividades, projetadas em açóes materiais, de modo que, o trabalho deste pesquisador experto estabelece uma sequência de produção de processos mentais cognitivos e sua concretização por meio de processos materiais.

A segunda parte do relato retrospectivo, quando o sujeito se vê diante do Replay do Translog, foi classificada sob o processo sócio-semiótico Explorar, uma vez que tem-se aumentado o grau de socialização destes significados produzidos em virtude de, para sua veiculação, terem de ser, necessariamente, aceitos pela comunidade discursiva (MATTHIESSEN et al., 2010). Assim, a análise se concentrou na interação entre pesquisador e sujeito.

A partir da descrição dos tipos de troca na interação realizada entre falantes, feita com base nos sistemas de FUNÇÓES DISCURSIVAS, MODO e VALIDAÇÃO (HALLIDAY, 1978) do português brasileiro (FIGUEREDO, 2011), analisaram-se as trocas de informaçóes entre os pesquisadores e o sujeito, que foram classificadas segundo os seguintes padróes.

\section{Padrão 1: confirmação de expectativas Confirmação de expectativas: do sujeito pelo pesquisador}

No caso do relato analisado, houve diversas situaçóes em que os significados produzidos pelo sujeito passaram, efetivamente, a fazer parte de seu discurso após serem validados pelo pesquisador, como se vê nos exemplos:

(5) Sujeito: E outra coisa aqui também fala "população negroide", né? Pesquisador: Um hum.

(6) Sujeito: aí eu...eu acho que náo alterou o sentido.

Pesquisador: Náo, não. 
(7) Sujeito: Aí out...outra situação que ele fala que é um...é... a anemia é uma anomalia genética importante no Brasil.

Pesquisador: Um hum.

Nestes casos, observa-se que as figuras ideacionais construídas pelo sujeito devem antes ser negociadas com o pesquisador, o que é feito, gramaticalmente, pela validação das proposiçôes. Além da declaração simples, outra forma comum de validação por parte do pesquisador de declarativas do sujeito foi o uso das Partículas Modais.

(8) Sujeito: E outra coisa aqui também fala "população negróide", né? Pesquisador: Um hum.

Sujeito: Tá vendo? Fica aqui, ó, anticorpo anti-HCV...né? Pesquisador: Certo.

O uso das Partículas Modais indica uma forma gramatical de negociação entre os falantes a qual aumenta a probabilidade de validação do que se propóe. Assim, quando o sujeito do experimento propóe seu processo de tradução através das proposiçóes validadas, abre a possibilidade para suas expectativas serem confirmadas ou frustradas pela validação do pesquisador com o qual interage.

\section{Confirmação de expectativas: do pesquisador pelo sujeito}

Observou-se a análise significados produzidos pelo pesquisador em seguida incorporados ao discurso por meio da validação do sujeito. Isto pode se dever ao fato de o pesquisador pensar no sujeito traços relevantes de expertise pela classificação a priori:

(10) Declarativa $\rightarrow$ validação

Pesquisador: É o que você tinha falado, do falcização.

Sujeito: É, isso. 


\section{(11) Declarativa validada $\rightarrow$ validação}

Pesquisador: Aqui você copiou foi pro Word, né isso?

Sujeito: É, foi.

(12) Declarativa validada + pergunta $\rightarrow$ validação + resposta

Pesquisador: Mas, aí você...você faz isso depois, né? Porque aqui você não colocou, assim, aqui que você fez, você deixou pra depois resolver? Sujeito: É, deixei pra depois resolver.

O pesquisador também se preocupa em identificar traços de expertise no sujeito, por meio de declaraçóes sobre as açóes tomadas pelo sujeito durante a tarefa tradutória que carecem de validação pelo sujeito para tomarem parte dos significados produzidos dentro do texto do relato. Destaca-se ainda que os recursos gramaticais utilizados pelo pesquisador para negociar os significados (ex: 10, 11, 12) são os mesmos que o sujeito (ex: 5, 6, 7, 8, 9), o que aponta para uma forma de cooperação entre ambos em sua negociação.

\section{Padrão 2: negociação}

Partindo da função complexa do Negociador, observa-se que em português brasileiro as orações indicativas são realizadas pelas funçóes de Sujeito + Finito, além de todas as oraçôes maiores iniciais apresentarem o Predicador (oração maior: +Predicador).

(13) Aí

\begin{tabular}{|l|l|}
\hline eu & tinha \\
\hline Sujeito & Finito \\
\hline \multicolumn{2}{|c|}{ MODO } \\
\hline
\end{tabular}

o termo técnico.

Uma vez que em português brasileiro as funções de Finito e Predicador podem vir confluídas em grupos verbais de apenas um verbo, tem-se como implicação a necessidade da inclusão do Predicador na interação, na configuração Sujeito + Finito/Predicador:

(14) Aí

\begin{tabular}{|l|l|}
\hline eu & encontrei \\
\hline Sujeito & Finito/Predicador \\
\hline MODO &
\end{tabular}


Disto decorre que o sistema de MODO não apenas encerra gramaticalmente a troca entre os interlocutores, como também negocia significados ideacionais (por meio da manutenção do Predicador na interação). Esta estrutura implica na realização de uma função semelhante a (13), porém com a presença do conteúdo ideacional, fazendo com que o Processo, se mantenha enquanto a interação se mantiver. A implicação desta propriedade gramatical do português brasileiro está no fato de uma figura do interlocutor ' $A$ ' influenciar a representação construída em outra figura do interlocutor ' $\mathrm{B}$ ':

\section{(15) Pesquisador: Aí você encontrou aqui?}

Sujeito: É, aí eu encontrei o termo...o termo técnico

É possível verificar que o Processo material 'encontrar' utilizado pelo pesquisador, por força da necessidade de se manter a interação teve de ser mantido na figura construída pelo sujeito (Quadro 2).

$$
\text { QUADRO } 2
$$

Elemento negociador na interação de (15).

\begin{tabular}{|l|l|l|}
\hline & Mudança & Manutençáo \\
\hline Sujeito (Responsável modal) & (você à eu) & \\
\hline Elemento Finito (desinência verbal) & $\left(2^{\text {a } \text { pessoa à } 1^{\text {a }} \text { pessoa) }}\right.$ & \\
\hline Predicador (Processo material 'encontrar') & & $\begin{array}{l}\text { (encontrar à } \\
\text { encontrar) }\end{array}$ \\
\hline
\end{tabular}

O padrão de negociação do corpus analisado é também construído na representação da tarefa tradutória. Matthiessen (2001) demonstra que a tradução é construída linguisticamente como uma atividade material de transformação, ou atividade relacional de identificação. Transformação: $\mathrm{X}$ se traduz por $\mathrm{Y} \rightarrow \mathrm{X}$ se transforma em Y. Identificaçấo: A tradução de $\mathrm{X}$ é $\mathrm{Y} \rightarrow \mathrm{X}$ é $\mathrm{Y}$. Por isto, as representaçooes construídas pelo pesquisador são naturalmente preservadas pelo sujeito do experimento na negociação.

A fala do sujeito sobre tradução é predominantemente material. A princípio, poderia ser esperado haver mais ocorrências de processos mentais, visto que as pesquisas em expertise são elaboradas segundo uma orientação cognitiva, portanto, procurando representaçóes mentais que, ao serem dispostas 
metaforicamente em esquemas, diagramas ou gráficos, possam elucidar o processo mental do sujeito durante a tarefa de tradução.

Contudo, pela forma como a negociação de significados é realizada gramaticalmente em português brasileiro, mantendo-se conteúdos ideacionais na interação, salvo quando houve conteúdos ideacionais de caráter mental na pergunta do pesquisador, não há probabilidade de o sujeito do experimento se referir ao seu processamento cognitivo durante a tarefa. Por isto, a representaçáo que o pesquisador em tradução possui da tarefa tradutória não escapa, em grande medida, da visão do senso comum sobre a tarefa - uma atividade transformacional ou de identificação:

(16) Pesquisador: Ok. Aí aqui já terminou.

Sujeito: Bom, aí eu terminei o que dava conta de fazer sozinho, né?

(17) Pesquisador: E a organização do texto, precisou mudar alguma coisa?

Sujeito: Náo, pouca coisa é... essencialmente porque o resumo é certo, acho que o resumo tá bom.

O pesquisador, através de uma declaração (16) e de uma pergunta (17), coloca à negociação significados ideacionais que o sujeito mantém. Os processos 'terminar' e 'mudar' são ambos materiais. Cabe notar que mesmo elíptico, o processo 'mudar' está presente na forma congruente de (17): "Não, [[precisei] mudar] pouca coisa". As falas do pesquisador representam a tarefa tradutória como atividades materiais de transformação e poderiam ser agnatas:

(18) agnata de (16)

Pesquisador: Ok. Aí aqui já transformou.

Sujeito: Bom, aí eu transformei o que dava conta de fazer sozinho, né?

(19) agnata de (17)

Pesquisador: E a organização do texto, precisou transformar alguma coisa? 
Sujeito: Náo, [[precisei] transformar] pouca coisa é... essencialmente porque o resumo é curto, acho que o resumo ta bom.

Como consequência desta padronização, tem-se a dificuldade de acesso ao processamento mental do sujeito durante o relato retrospectivo dialogado quando assiste ao Replay do Translog, devido à natureza da interação entre pesquisador e sujeito.

É natural entender que seja necessário investigar os Processos Mentais do sujeito para se ter acesso a seu processamento cognitivo, uma vez que o subgrupo dos Processos Mentais Cognitivos respondem pela representação que construímos de nossos pensamentos, exteriorizados linguisticamente como projeção de ideias:

(20) Sujeito: Acho <Mental Cognitivo> que [projeção: ideia] esse termo não existe.

(21) Sujeito: Eu acho <Mental Cognitivo>que [projeção: ideia] não alterou o sentido.

A partir destas considerações sobre Processos Mentais Cognitivos é possível entender que sua análise pode oferecer subsídios para a compreensão do processamento cognitivo do sujeito sobre a tarefa tradutória:

(22) Pesquisador: Mas mudou por que você não sabia <Mental Cognitivo > construir ou você achou $<$ Mental Cognitivo $>$ melhor?

Sujeito: Não sabia<Mental Cognitivo>, essa construção eu não sei $<$ Mental Cognitivo $>$ fazer.

A estimulação à interação expressa pelo pesquisador sob forma de uma pergunta, apresenta duas figuras ideacionais mentais cujos Processos são Mentais Cognitivos, nos grupos verbais 'saber construir' e 'achar'. Segundo a configuração gramatical da interação em português brasileiro, proposiçóes como esta do pesquisador fazem com que o Processo Mental Cognitivo se mantenha na figura que o sujeito produz em seguida.

Uma outra estrutura comum na representação que o sujeito constrói de sua tarefa pode ser observada quando esta não faz parte da negociação, mas constitui proposição à parte, como no caso do exemplo (17). 
Retomando o exemplo (17):

Pesquisador: E a organização do texto, precisou mudar alguma coisa?

Sujeito: Náo, pouca coisa é... essencialmente porque o resumo é certo, acho que o resumo tá bom.

Após manter o Processo Material produzido pelo pesquisador, o sujeito avança no discurso, produzindo novos significados: "essencialmente porque o resumo é curto" e "acho que o resumo tá bom". Por meio do Processo Relacional 'é, estabelece a relação entre o resumo e um Atributo, 'curto', realizado por um Epíteto Ideacional, cuja função é indicar um subgrupo do Ente ao qual concede uma qualidade.

Em seguida, o sujeito constrói uma figura Mental Cognitiva que projeta uma ideia, novamente dando um Epíteto ao resumo, "acho $<$ Cognitivo $>$ que o resumo tá bom <Atributo: Epíteto Interpessoal>". Entretanto, neste segundo caso, o Epíteto possui orientação interpessoal, pois expressa a avaliação subjetiva sobre o Ente ao qual qualifica. Com este exemplo pode-se observar a produção de significados pelo sujeito para além da organização gramatical da negociação do português brasileiro. Contrastivamente tem-se:

\section{QUADRO 3}

Análise de (17) frente à Negociação

\begin{tabular}{|l|l|}
\hline NEGOCIAÇÃO (+) & NEGOCIAÇÃO (-) \\
\hline$\rightarrow$ Manutenção do Predicador & $\rightarrow$ Construção de diferentes figuras \\
$\rightarrow$ Atividade material na tarefa de tradução & $\rightarrow$ Representaçóes de relação ideacional \\
$\rightarrow$ Operação gramatical simples sem acesso & entre itens \\
ao processamento cognitivo do sujeito & $\rightarrow$ Expressão de avaliação \\
& $\rightarrow$ Construção Mental Cognitiva \\
& $\rightarrow$ Projeção de ideia \\
\hline
\end{tabular}

Por conseguinte, a produção do sujeito, quando dá início a uma nova negociaçáo, pode vir a oferecer mais dados à análise do relato retrospectivo. No corpus, este fenômeno ocorreu em outras oportunidades, como:

(23) Acho que esse termo náo existe.

(24) Eu acho que não alterou o sentido. 
Os exemplos 23 e 24 apontam para uma atividade predominante cognitiva, que pode projetar relaçóes: "acho que o resumo tá bom”; existência: "acho que esse termo não existe"; açôes materiais: "eu acho que não alterou o sentido".

\section{Padrão 3: tomada de turno}

$\mathrm{Na}$ interação entre o pesquisador e o sujeito do experimento foi observado que a tomada de turno possui a função de negociar significados na interação, o que pode ser feito por complementação, refutação e realce.

Em termos ideacionais, a tomada de turno engendra implicaçóes relativas à construção das figuras. A figura é composta por um núcleo, que é Processo, o Participante e as Circunstâncias de variados tipos, como Modo, Localização, entre outras:

$(25)$

\begin{tabular}{|l|l|l|l|}
\hline A anemia & é & uma anomalia genética importante & no Brasil \\
\hline Participante & Processo & Participante & $\begin{array}{l}\text { Circunstância: } \\
\text { Localização }\end{array}$ \\
\hline FIGURA & \multicolumn{2}{|l|}{} \\
\hline
\end{tabular}

(26)

\begin{tabular}{|l|l|}
\hline Você & tinha falado \\
\hline Participante & Processo \\
\hline FIGURA & \\
\hline
\end{tabular}

Quando apenas um dos interlocutores faz, por exemplo, uma declaração, ou pergunta, expressa a figura completa, com todos os seus elementos. Já na tomada de turno, a figura é construída por mais de um interlocutor, como no caso do corpus analisado, no qual um dos padróes encontrados foi o de figuras construídas pelo sujeito e pelo pesquisador:

(27) Sujeito: Eu fui deixando as dúvidas pra...

Pesquisador: Pra depois?

Sujeito: Pra depois. 
(28) Sujeito: Eu corrigi na...no...no...no...

Pesquisador: No Word.

Sujeito: No Word.

Pesquisador: Ahã.

Nestes dois exemplos, o pesquisador, juntamente com o sujeito responsável pela representação da experiência que seria, supostamente, do sujeito. Na análise as sequências destas interações, verifica-se que as circunstâncias acrescentadas na tomada de turno são proposiçóes negociadas pelo pesquisador junto ao sujeito:

Sujeito: Eu fui deixando as dúvidas pra... [DECLARAÇÃO].

Pesquisador: Pra depois? [TOMADA DE TURNO / CIRCUNSTÂNCIA; PERGUNTA].

Sujeito: Pra depois? [CIRCUNSTÂNCIA; VALIDAÇÃO].

É possível entender, passo a passo, como um significado (no caso, a circunstância) é proposto, negociado e validado. No outro exemplo, ainda se observa a validação do sujeito sendo interpretada pelo pesquisador como declaração e, novamente, sendo validada:

Sujeito: Eu corrigi na...no...no...no... [DECLARAÇÃO]

Pesquisador: No Word. [TOMADA DE TURNO/CIRCUNSTÂNCIA; DECLARAÇÃO]

Sujeito: No Word. [CIRCUNSTÂNCIA; VALIDAÇÃO/ DECLARAÇÃO]. Pesquisador: Ahã. [VALIDAÇÃO].

\section{Considerações finais}

Este trabalho investigou os relatos retrospectivos dialogados de um sujeito experto em sua área de atuação que realiza traduçóes como parte de suas atividades. Por ser reconhecido como pesquisador experto pelos pares e por sua longa experiência, esse sujeito pôde ser, segundo critérios adotados por Ericsson et al. (2006), classificado como experto também em tradução. A classificação, realizada no âmbito do projeto EXPERT@, foi feita a priori, 
necessitando tal hipótese, para ser confirmada, da realização do experimento com o sujeito e subsequente análise dos dados coletados sobre a tarefa tradutória.

Procurando servir a este tipo de pesquisa, com uma análise sócio-semiótica da transcrição do relato, este trabalho descreveu padróes encontrado no corpus que apontam para a construção semiótica do sujeito experto em tradução.

Os resultados dessa análise mostram como o sujeito do experimento é constituído como experto de duas formas principais. Em primeiro lugar, a necessidade de classificação do sujeito como experto, com base no reconhecimento pelos pares e na experiência, a priori, levou à montagem do relato retrospectivo, por parte dos pesquisadores, como uma forma de se averiguar o desenvolvimento da expertise no sujeito pela experiência e pela habilidade durante o desempenho pela tarefa. $\mathrm{O}$ desenvolvimento da experiência e o reconhecimento social puderam ser verificados mediante a análise do corpus relativa ao processo sócio-semiótico Relatar; já o desempenho foi constatado por meio da investigação do processo Explorar.

Em segundo lugar, o diálogo entre pesquisador e sujeito constituiu-se, basicamente, como uma negociação de significados que se produziram face à necessidade de construção do sujeito enquanto experto em tradução. Por meio de mecanismos de interação sócio-semióticos (portanto, semânticos e lexicogramaticais), observou-se no relato analisado a produção de significados por parte de um dos interlocutores, a sua negociação e a subsequente validação deles por parte do outro interlocutor.

Destacou-se a forma como o sujeito, estimulado pelas perguntas constrói sua experiência como experto, o que foi feito, basicamente, por uma combinação de atividades mentais que produzem atividades materiais. Já na negociação, o sujeito experto foi construído pela interação entre o pesquisador e o sujeito do experimento. Quando se realizam experimentos sobre o conhecimento experto, espera-se, diante do Replay do Translog, que o relato indique alguma atividade do tradutor característica do experto, como, por exemplo, sua capacidade de auto-monitoramento durante a tarefa tradutória. Desta maneira, a interaçáa entre o pesquisador e o sujeito pôde se dar no sentido de construir um relato capaz de indicar momentos nos quais houve atividades realizadas pelo tradutor que o caracterizam como experto. 
Do ponto de vista gramatical, isto se observou em como um conteúdo ideacional produzido pelo pesquisador foi retomado como parte do discurso do sujeito, de forma que o relato pudesse indicar uma verbalização do sujeito compatível com a de um experto.

\section{Referências}

ALVES, F; MAGALHÁES, C. Investigando o Papel do Monitoramento Cognitivo-Discursivo e da Meta-Reflexão na Formação de Tradutores. Cadernos de tradução, s.n., 2006.

ALVES, F. A triangulação como opção metodológica em pesquisas empírico-experimentais em tradução. In. PAGANO, A. (Org.). Metodologias de pesquisa em tradução. Belo Horizonte: Faculdade de Letras, UFMG, 2001.

ALVES, F.; MAGALHÁES, C.; PAGANO, A. Conhecimento experto em tradução: modelagem do processo tradutório em altos níveis de desempenho EXPERT@. Belo Horizonte: Faculdade de Letras/UFMG, 2006. Inédito.

$\mathrm{CHI}, \mathrm{M}$. Two approaches to the study of expert's characteristics. In: ERICSSON, K. et al. The Cambridge handbook of expertise and expert performance. Cambridge: Cambridge University Press, 2006. p. 21-30.

DIMITROVA, B. Expertise and explicitation in the translation process. Amsterdã: John Benjamins, 2005.

ERICSSON, K.; CHARNESS, N.; FELTOVICH, P.; HOFFMAN, R. The Cambridge handbook of expertise and expert performance. Cambridge: Cambridge University Press, 2006.

ERICSSON, K.; SMITH, J. Prospects and limits of the empirical study of expertise: an introduction. In: ERICSSON, K.; SMITH, J. Toward a general theory of expertise. Cambridge: CUP, 1991. p. 1-38.

FIGUEREDO, G. Introdução ao perfil metafuncional do português brasileiro: contribuiçôes para os estudos multilíngues. 2011. 383 f. Tese (Doutorado em Linguística Aplicada) - Faculdade de Letras, Universidade Federal de Minas Gerais, Belo Horizonte, 2011.

HALLIDAY, M. Language as social semiotic: the social interpretation of language and meaning. London \& Baltimore: Edward Arnold \& University Park Press, 1978.

HALLIDAY, M.; MATHIESSEN, C. An introduction to functional grammar. 4. ed. London: Edward Arnold, 2004. 
HALLIDAY, M.; MATTHIESSEN, C. Construing experience through meaning: a language-based approach to cognition. London: Cassell, 1999.

HERKE-COUCHMAN, M. SFL, corpus and the consumer: an exploration of theoretical and technological potential. Sidney: Departamento de Linguística/ Macquire University, 2006. (Tese de doutorado).

HOFFMAN, R.; LINTERN, G. Eliciting and representing the knowledge of experts. In: ERICSSON, K. A. et al. The Cambridge handbook of expertise and expert performance. Cambridge: Cambridge University Press, 2006. p. 203-222.

HOLMES, J. S. The name and nature of Translation Studies. In: HOLMES, J. S. Translated Papers on Literary Translation and Translation Studies. Amsterdâ: Rodopi, 1972. p. 67-80.

JAKOBSEN, A. Effects of thinking aloud on translation speed, revision and segmentation. In: ALVES, F. (Ed.) Triangulating translation: perspectives in process oriented research. Amsterdam: John Benjamins, 2005. p. 69-95.

MATHIESSEN, C. The environments of translation. In: Steiner, E., YALLOP, C. (Ed.). Exploring translation and multilingual text production: beyond content. Berlin, New York: Mouton de Gruyer, 2001. p. 41-124.

MATTHIESSEN, C. Construing processes of consciousness. From the commonsense model to the uncommonsense model of cognitive science. In: MARTIN, J., VEEL, R. (Ed.). Reading science; critical and functional perspectives on discourses of science. London and New York: Routledge, 1998. p. 327-356.

MATTHIESSEN, C.; TERUYA, K.; LAM, M. Key terms in systemic-functional linguistics. Londres e Nova York: Continuum, 2010.

MATTHIESSEN, C.; TERUYA, K.; WU, C. Multilingual studies as a multi-dimensional space of interconnected language studies. In: WEBSTER, J. (Ed.). Meaning in Context: implementing intelligent applications of language studies. London and New York: Continuum, 2008.

MUNOZZ, R. Expertise and environment in translation (PETRA). Mutatis Mutandis. vol 2, n. 1. 2009. p. 24-37.

SHREVE, G. The deliberate practice: translation and expertise. Journal of Translation Studies, n. 9(6), p. 27-42, 2006.

SOSNIAK, A. Retrospective interviews in the study of expertise and expert performance. In: ERICSSON, K. A. et al. The Cambridge handbook of expertise and expert performance. Cambridge: Cambridge University Press, 2006. p. 287-318. 


\title{
CONSTRUING THE EXPERT TRANSLATOR SOCIO- SEMIOTICALLY: ENACTMENT AND REPRESENTATION IN RETROSPECTIVE PROTOCOLS
}

\begin{abstract}
This paper explores the contributions of a socio-semiotic approach (Halliday, 1978) to the studies of expertise in translation (Dimitrova, 2005). More specifically it analyses the textual production concerning the expert character of translators. It shows how the meaning produced collectively by translator and researcher are the language base of expertise (Matthiessen, 1998).

KEYWORDS: Descriptive Translation Studies; Expetise in Translation; Socio-Semiotic Construal.
\end{abstract}

Recebido em: 27/08/2013

Aprovado em: 18/11/2013 